\title{
Quantifying the vertical microclimate profile within a tropical seasonal rainforest, based on both ground- and canopy-referenced approaches
}

\author{
Yun Deng ${ }^{(1-2-3-4)}$, \\ Jinlong Dong ${ }^{(1-2-4)}$, \\ Wenfu Zhang ${ }^{(1-2-4)}$, \\ Shengdong Yuan ${ }^{(1-2-4)}$, \\ Zhenghong $\operatorname{Tan}^{(5)}$, \\ Qinghai Song ${ }^{(1-2)}$, \\ Xiaobao Deng ${ }^{(1-2)}$, \\ Min Cao ${ }^{(1-2)}$
}

\begin{abstract}
Quantifying the microclimate of a tall and complex tropical forest is quite challenging because of the difficulty in accessing the canopy. Traditional ground-referenced methods may underestimate the contribution of canopy heterogeneity to structuring the vertical profiles of forest microclimate. The present study examined how the reference height affects vertical variation of microclimate in a tropical rainforest in southwest China, based on both ground- and canopy-referenced approaches. The results show that the canopyreferenced approach yielded a higher model fit than did the ground-referenced method, and only canopy-referenced method could detect two thresholds in the leaf area index at approximately $-22.6 \pm 2.7 \mathrm{~m}$ and $-36.6 \pm 6.6 \mathrm{~m}$ below the canopy top; the higher threshold is consistent with thresholds of the annual mean temperature, the diurnal ranges of air temperature, and the relative humidity in the vertical profile; while the lower threshold is similar with the breakpoints of annual mean relative humidity, the annual ranges of air temperature and the relative humidity along the profile. The discontinuous variance in the microclimatic factors was due to the canopy structure in the vertical profile. Selecting the top of the canopy as the reference height could be a better approach for quantifying the microclimatic profiles in the studied forest, and this approach can improve our understanding of the effects of the vertical stratification of microclimates on species composition and diversity in this forest.
\end{abstract}

Keywords: Tropical Seasonal Rainforest, Vertical Gradient, Light Environment, Temperature And Humidity, Distance From The Canopy Surface

and microclimate interactions at smaller scales (Nakamura et al. 2017).

Although the transmission of radiation affects the microclimate in the forest understory, most previous studies have taken the ground as a reference due to the difficulty of accessing the forest canopy. These ground-level measurements may underestimate the microclimatic edge effects on vertical stratification in forests (Didham \& Ewers 2014). As radiation is attenuated

(1) CAS Key Laboratory of Tropical Forest Ecology, Xishuangbanna Tropical Botanical Garden, Chinese Academy of Sciences, Mengla, Menglun 666303, Yunnan (China); (2) Center for Plant Ecology, Core Botanical Gardens, Chinese Academy of Sciences, Mengla, Menglun 666303, Yunnan (China); (3) Department of Life Sciences, University of Chinese Academy of Sciences, Beijing 100049 (China); (4) National Forest Ecosystem Research Station at Xishuangbanna, Xishuangbanna Tropical Botanical Garden, Chinese Academy of Sciences, Mengla, Menglun 666303, Yunnan (China); (5) Department of Environmental Sciences, Hainan University, Haikou 570228 (China)

@ Min Cao (caom@xtbg.ac.cn)

Received: Feb 10, 2021 - Accepted: Nov 26, 2021

Citation: Deng Y, Dong J, Zhang W, Yuan S, Tan Z, Song Q, Deng X, Cao M (2022). Quantifying the vertical microclimate profile within a tropical seasonal rainforest, based on both ground and canopy-referenced approaches. iForest 15: 24-32. - doi: 10.3832/ifor3780-014 [online 2022-01-27]

Communicated by: Tamir Klein

from the top of the canopy to the understory, ground-referenced radiation transfer models limit the estimation of microclimate factors when used in the canopy height model (CHM), although the $\mathrm{CHM}$ can extract the vegetation structure at both the plot level and the individual plant level (Poley \& McDermid 2020).

Many studies have suggested that vertical radiation transmission in forest canopies can be described by Beer's law (Baldocchi \& Collineau 1994, Yirdaw \& Luukkanen 2004), and the transmittance of diffuse light in the forest has an exponential relationship with the aboveground height (Kenzo et al. 2015). However, at the fundamental biophysical level, Beer's law describing the radiation absorbed by the canopy was believed oversimplified, particularly in the case of highly heterogeneous canopies and those with significant foliage clumping (Landsberg \& Sands 2011), because high rugosity is a common feature of old-growth forests (Parker et al. 2019). The amount of solar radiation received at the canopy floor is largely dependent on the leaf area index (LAI) of the forest, but approximately $50 \%$ of the total leaf area in forests has been reported to be concentrated within a depth of $5 \mathrm{~m}$ from the top of the canopy (Wirth et al. 2001), and the relationship between the LAl and the height of a forest is not linear. The discon- 
tinuous profile of the LAI further complicates the transmission of radiation in the understory, especially in tropical forests, which canopy was high and quite heterogeneous.

Radiation reduction in a forest also affects other environmental factors such as air temperature and humidity, and these microclimatic factors may affect the productivity and biodiversity of different height layers. The spatial and temporal variation in air temperature is qualitatively similar to the variation in photon flux density (Bazzaz \& Wayne 1994). In addition, temperature is a key determinant of the rate of metabolic processes and hence has a major impact on carbon balance, as a consequence of photosynthesis and respiration (Landsberg \& Sands 2011). Relative humidity $(\mathrm{RH})$, another important factor that is affected by radiation and temperature, determines the water loss from transpiration and affects the photosynthesis and respiration of plants (Landsberg \& Sands 2011). Plants grown at high RHs (RH $\geq 85 \%)$ frequently show a rapid wilting trait when exposed to lower RHs ( $\approx 60 \%$ - Fanourakis et al. 2020). The vertical gradient in the species composition of bryophytes is strongly associated with the decreasing gradient of $\mathrm{RH}$ and other microclimate factors (Shen et al. 2018); and amphibians prefer shaded, cool, and moist habitats on the forest floor (Brooks \& Kyker-Snowman 2008). However, quantitative studies of species distribution patterns in the vertical gradient are limited, the vertical composition of biodiversity in forests is not well understood, and more accurate microclimate profiles are needed.

In a seasonal rainforest in Xishuangbanna, southwest China, the transmitted radiation that eventually reaches the understory surface was reported to be approximately $7.13 \%$ of the total radiation (Zhang et al. 2005). Compared to full-light conditions, the total solar radiation, infrared radiation, and daily radiation of visible light into the canopy were all decreased as height descended (Dou et al. 2006), resulting in higher temperature in upper canopy and lower temperature in lower canopy (Yang et al. 2009). However, the heterogeneity of the canopy height in the forest is quite substantial, and the height difference between the emergent layer (Parashorea chinensis, approximately $60 \mathrm{~m}$ high) and the upper canopy layer (approximately $30 \mathrm{~m}$ high) exceeds 20 m (Cao \& Zhang 1997, Cao et al. 2008). We also observed that the transmittance diffuse light varied from $0.3 \%$ at $3.7 \mathrm{~m}$ to $100 \%$ at $\geq 21.2 \mathrm{~m}$ based on the recent measurements using a canopy crane in this forest (Deng et al. 2020). Early studies that used the ground as a reference for measuring the variations in vertical microclimate, however, may still be insufficient to quantitatively describe the within-forest vertical profile of microclimate, although these features are very important for understanding and explaining the high biodiversity in the forest.

In the present study, we tried to examine the change in the microclimate ranging from the top canopy to the ground (forest floor), demonstrating the trajectory of topdown variation in the factors. We hypothesized that the height and distance downward to the ground affect the microclimate within the forest and that the major factors of vertical microclimate exhibit discontinuous variance based on the nonlinear attenuation of radiation in the vertical profile. A canopy crane was used to investigate the vertical profiles at the study site, and both the distance to the canopy surface and the distance to the ground of each point at the profile were recorded. By comparing variations in biophysical factors such as the LAI, the diffuse non-interceptance (DIFN), the ratio of red to far-red light ( $R: F R$ ratio), the air temperature, and the $\mathrm{RH}$ in the profile, we sought to understand the differences between canopy-referenced and ground-referenced methods and to develop an approach for determining the vertical profiles of forest microclimates.

\section{Materials and methods}

\section{Overview of the study area}

This study was carried out in the crane plot in the tropical seasonal rainforest of Xishuangbanna (101 $34^{\circ} 59.1^{\prime \prime} \mathrm{E}, 21^{\circ} 37^{\prime} 2.6^{\prime \prime}$ $\mathrm{N}$; altitude $653.4 \mathrm{~m}$ a.s.l.). This plot was established in December 2014, approximately $300 \mathrm{~m}$ from the Xishuangbanna tropical seasonal rainforest 20-ha dynamics plot (XTRDP). The height of the canopy crane (TCT7015-10E, Zoomlion, Changsha, China) is $80 \mathrm{~m}$ (approximately $20 \mathrm{~m}$ higher than the canopy of emergent trees), and the jib length is $60 \mathrm{~m}$. A long-term monitoring plot of $120 \times 120 \mathrm{~m}$ was built up around the canopy crane. According to the results of a survey in 2014, there were 6928 individual trees with diameter at breast height (DBH) $\geq 1 \mathrm{~cm}$ in this plot, belonging to 55 families and 217 species (Deng et al. 2020). The tree species composition of the crane plot is close to that of the XTRDP (Cao et al. 2008), and $P$. chinensis has the highest relative importance value (21.73\%) in this plot.

\section{Measurement of the vertical light} environment

With the assistance of the canopy crane, we set 40 vertical light environmental survey profiles (Fig. S1 in Supplementary material) in three concentric circles with radii of 20,40 , and $56 \mathrm{~m}$ respectively. For the two outer circles, the profiles were spaced every $22.5^{\circ}$ horizontally; and for the inner circle, the profiles were spaced every $45^{\circ}$ horizontally. At each vertical survey profile, the light environment was measured every $5 \mathrm{~m}$ of interval, from the top of the tower crane $(80 \mathrm{~m})$ down to the ground. The height from the canopy $\left(\mathrm{H}_{\text {canopy }}\right)$ and height to the ground $\left(\mathrm{H}_{\text {ground }}\right)$ at each measurement point were recorded. The maximum canopy height at all 40 vertical investigation profiles was between 15.0 and $63.5 \mathrm{~m}$, with a mean ( \pm standard deviation) of 34.8 $\pm 14.6 \mathrm{~m}$.

Since the actual measurement plane is located at the top of the hanging basket, the lowest measuring position in each profile was approximately $2 \mathrm{~m}$ above the ground.

The spatiotemporal distribution of light in the understory is quite heterogeneous, and the measurement of direct light is difficult for long-term sampling (Engelbrecht \& Herz 2001). Indirect measurements, such as the transmittance of diffuse light (presented as the DIFN), are also acceptable for estimating light conditions. The DIFN is a single-value representation of the canopy structure because it combines the LAI and the mean tilt angle of leaves (MTA) into one number (LI-COR 2021). A previous methodological comparison showed that the DIFN had a good fit with the directly measured long-term photosynthetic photon flux density (PPFD) in the understory of a tropical forest (Engelbrecht \& Herz 2001). In this study, both the DIFN and LAI were measured using the plant canopy analyzer $\mathrm{LI}-2200 \mathrm{C}^{\oplus}$ (LI-COR, Inc., Lincoln, NE, USA). Open sky measurements were conducted at the top of the crane, and each profile was measured at the highest working height of the tower crane with five replicates. A $270^{\circ}$ view cap was used to prevent the crane jib from obstructing the view. The repeated measurements of each measuring point were used to adjust the open sky measurements with $\mathrm{FV} 2200^{\circledast}$ software (LI-COR, Inc., Lincoln, NE, USA) and to estimate the DIFN and LAI. The measurements were repeated five times at each height of each profile.

The leaves of the canopy absorb much more light in the photosynthetically active portion of the spectrum $(400-700 \mathrm{~nm})$ than in the near-infrared range $(700-1000 \mathrm{~nm}-$ Lee 1989, Pons 1992), which shifts the ratio of red to far-red wavelengths in the understory (Pons 1992). Occasional light flecks can have a significant effect on the average daily PPFD, but these flecks have little effect on daily R:FR ratios (Turnbull \& Yates 1993, Capers \& Chazdon 2004), which indicates that the R:FR ratio can be used in assessing light levels in the understory ( $\mathrm{Ca}$ pers \& Chazdon 2004). The R:FR ratio was measured by a SpectroSense $2+{ }^{\circledR}$ spectrometer (Skye Instruments Ltd, Wales, UK). The measurements were repeated five times at each height of each profile, and the mean value was taken as the corresponding light environment at this position.

The measurements of the DIFN, LAI and R:FR ratio were carried out and accomplished in April 2016 from approximately 10:00 to $16: 00$ on sunny days, when it is in the end of the dry season.

\section{Vertical temperature and humidity profiles}

Three vertical profiles were set up, which 
included three emergent $P$. chinensis individuals in different directions around the crane (where the maximum heights of the canopy were $56.5,62.7$, and $63.1 \mathrm{~m}$, respectively). The air temperature and $\mathrm{RH}$ were recorded by an Onset $\mathrm{HOBO} \mathrm{U}_{23}-001^{\oplus}(\mathrm{ON}$ SET, USA). Sensors were set at following levels: (i) For the individual of $56.5 \mathrm{~m}: 2 \mathrm{~m}$, $12 \mathrm{~m}, 22 \mathrm{~m}, 32 \mathrm{~m}, 42 \mathrm{~m}$ (lower crown), $47 \mathrm{~m}$ (middle crown), and $54.5 \mathrm{~m}$ (upper crown); (ii) For the individual of $62.7 \mathrm{m:} 2 \mathrm{~m}, 12 \mathrm{~m}$, $22 \mathrm{~m}, 32 \mathrm{~m}, 42 \mathrm{~m}$ (lower crown), $52.5 \mathrm{~m}$ (middle crown), and $58.7 \mathrm{~m}$ (upper crown); (iii) For the individual of $63.1 \mathrm{m:} 1.5 \mathrm{~m}, 11.5$ $\mathrm{m}, 21.5 \mathrm{~m}, 31.5 \mathrm{~m}, 41.5 \mathrm{~m}, 51.5 \mathrm{~m}$ (lower crown), $55 \mathrm{~m}$ (middle crown), and $60.5 \mathrm{~m}$ (upper crown).

In total, 22 sensors were installed in the forest to continuously monitor changes in the air temperature and humidity in these four profiles. The measurements were performed every $30 \mathrm{~min}$. A radiation shield was used to protect the sensor from direct sunlight to prevent data drift. This study used data from May 27, 2016 to December 31, 2019 (the data from January to May 2016 and from December 2018 to February 2019 were missing, so they were extrapolated from previous annual means).

\section{Data analysis}

Five temperature indices, i.e., annual mean temperature (AMT), monthly mean temperature (MMT), monthly (MDRT) and annual mean diurnal range of temperature (ADRT), and mean annual range of temperature (MART), and five humidity indices, i.e., annual mean RH (AMRH), monthly mean RH (MMRH), monthly (MDRRH) and annual mean diurnal range of RH (ADRRH), and mean annual range of RH (MARRH), were computed to investigate the vertical and temporal changes in the air temperature and humidity. The MMT and MMRH were averaged arithmetically according to the daily mean values (the average values of 48 records per day, and one record per $0.5 \mathrm{~h}$ ) of the temperature and $\mathrm{RH}$ in each month from January 2016 to December 2019. The AMT (or AMRH) was the arithmetical average of $4 \times 12 \mathrm{MMT}$ (or MMRH) values. The MDRT (or MDRRH) was the mean value of the diurnal range of temperatures (DRT - or RH, DRRH - the difference between the daily maximum and minimum temperatures or $\mathrm{RH}$ ) in each month from January 2016 to December 2019, and the ADRT (or ADRRH) was the mean value of 4 $\times 12$ MDRT (or MDRRH) values. The annual range of temperature (ART - or the annual range of $\mathrm{RH}, \mathrm{ARRH}$ ) was the difference between the MMTs (or MMRHs) of the warmest and coldest months within a year, and the MART (or MARRH) was the mean value of the ART (or ARRH) from 2016 to 2019.

Microclimatic factors in the crane plot are summarized in Tab. S1 (Supplementary material). The nonparametric locally estimated scatterplot smoothing (LOESS) model was used to approximate the number and positions of the breakpoints in light-related data between heights, and a piecewise linear regression model (PLRM) was used to estimate the breakpoints for LAI, DIFN, R:FR ratio, AMT, ADRT, MART, AMRH, ADRRH and MARRH in each vertical gradient. The LOESS model was fitted using the statement "loess" in R (R Core Team 2020), and the PLRM was implemented using the R package "segmented" (Muggeo 2021).

To estimate breakpoints incorporating linear segments, the PLRM was expressed as follows (Tomal \& Ciborowski 2020 - eqn. 1):

$$
\begin{aligned}
y_{1}= & \beta_{o}+\beta_{1} x_{1} \\
& \text { for } x \leq \alpha_{1} \\
y_{2}= & \beta_{0}+\beta_{1} x_{2}+\beta_{2}\left(x_{2}-\alpha_{1}\right) \\
& \text { for } \alpha_{1}<x \leq \alpha_{2} \\
y_{3}= & \beta_{0}+\beta_{1} x_{3}+\beta_{2}\left(x_{3}-\alpha_{1}\right)+\beta_{3}\left(x_{3}-\alpha_{2}\right) \\
& \text { for } x>\alpha_{2}
\end{aligned}
$$

where $y$ and $x$ are the values for the response and predictor variables, respectively; $\alpha_{1}$ and $\alpha_{2}$ are the breakpoints; and $\beta_{1}$, $\beta_{1}+\beta_{2}$ and $\beta_{1}+\beta_{2}+\beta_{3}$ are the slopes of linear regression models 1,2 and 3 , respectively. The thresholds and slopes for the PLRM are listed in Tab. S2 and Tab. S3 (Supplementary material). $R$ (v. 4.0.5) was used to perform model fitting and to calculate the relevant model parameters ( $R$ Core Team 2020).

\section{Results}

\section{Light environment}

When the ground was used as the reference, the LAl was highest at $2 \mathrm{~m}$ above ground (estimate $\pm \mathrm{SE}=4.81 \pm 0.97$ ) and rapidly decreased with decreasing height until a height of $19.0 \pm 1.6 \mathrm{~m}$ (Fig. 1a). When the height was over $19 \mathrm{~m}$, the slope of LAI vs. height became gentler as the LAI began to stabilize somewhat. When the canopy was used as the reference, the LAI increased dramatically from the canopy surface $(0 \mathrm{~m})$ to $-22.6 \pm 2.6 \mathrm{~m}$ below the canopy top. The LAl was relatively stable at $\mathrm{H}_{\text {canopy }}$ values lower than $-22.6 \pm 2.6 \mathrm{~m}$ and higher than $-36.6 \pm 6.6 \mathrm{~m}$, but then the slope of LAI vs. height became steep again below $-36.6 \pm 6.6 \mathrm{~m}$ (Fig. 1b).

DIFN gradually increased with increasing $\mathrm{H}_{\text {ground, }}$ and from $\mathrm{H}_{\text {ground }}=26.2 \pm 3.6 \mathrm{~m}$ upward, the slope of DIFN vs. height became flatter (Fig. 1C). When using $\mathrm{H}_{\text {canopy }}$ for reference, however, DIFN increased gently with increasing height from forest floor to -14.0

(1) $\pm 2.0 \mathrm{~m}$ high and rapidly increased from $-14.0 \pm 2.0 \mathrm{~m}$ to the top canopy (Fig. 1d). In addition, DIFN was not saturated at the canopy surface, showing a value of $76.95 \pm$ $24.19 \%$ at $\mathrm{H}_{\text {canopy }}=0 \mathrm{~m}$.

The R:FR ratio at $2 \mathrm{~m}$ above the forest floor was $0.557 \pm 0.173$, and it increased with increasing $\mathrm{H}_{\text {ground }}$ until it slowed down at the height of $21.2 \pm 3.3 \mathrm{~m}$ (Fig. 1e). In terms of $\mathrm{H}_{\text {canopy }}$, the curve of the R:FR ratio vs. height exhibited two breakpoints, at $-13.0 \pm 2.5 \mathrm{~m}$ and $-43.8 \pm 6.8 \mathrm{~m}$ in height (Fig. 1f), and the R:FR ratio only showed greater stability between these two breakpoints.

\section{Vertical variation in air temperature}

The AMT exhibited a linear increase with increasing height from the ground until the height of $46.2 \pm 7.9 \mathrm{~m}$ (Fig. $2 \mathrm{a}$ ) or $-16.7 \pm 6.5$ $\mathrm{m}$ under the canopy surface (Fig. $2 \mathrm{~b}$ ), then became relatively stable in the upper canopy. The PLRM exhibited a better fit $\left(r^{2}\right.$ $=0.9260$ ) compared to when the ground was used as the reference $\left(r^{2}=0.8519\right)$.

The breakpoint where the ADRT slope

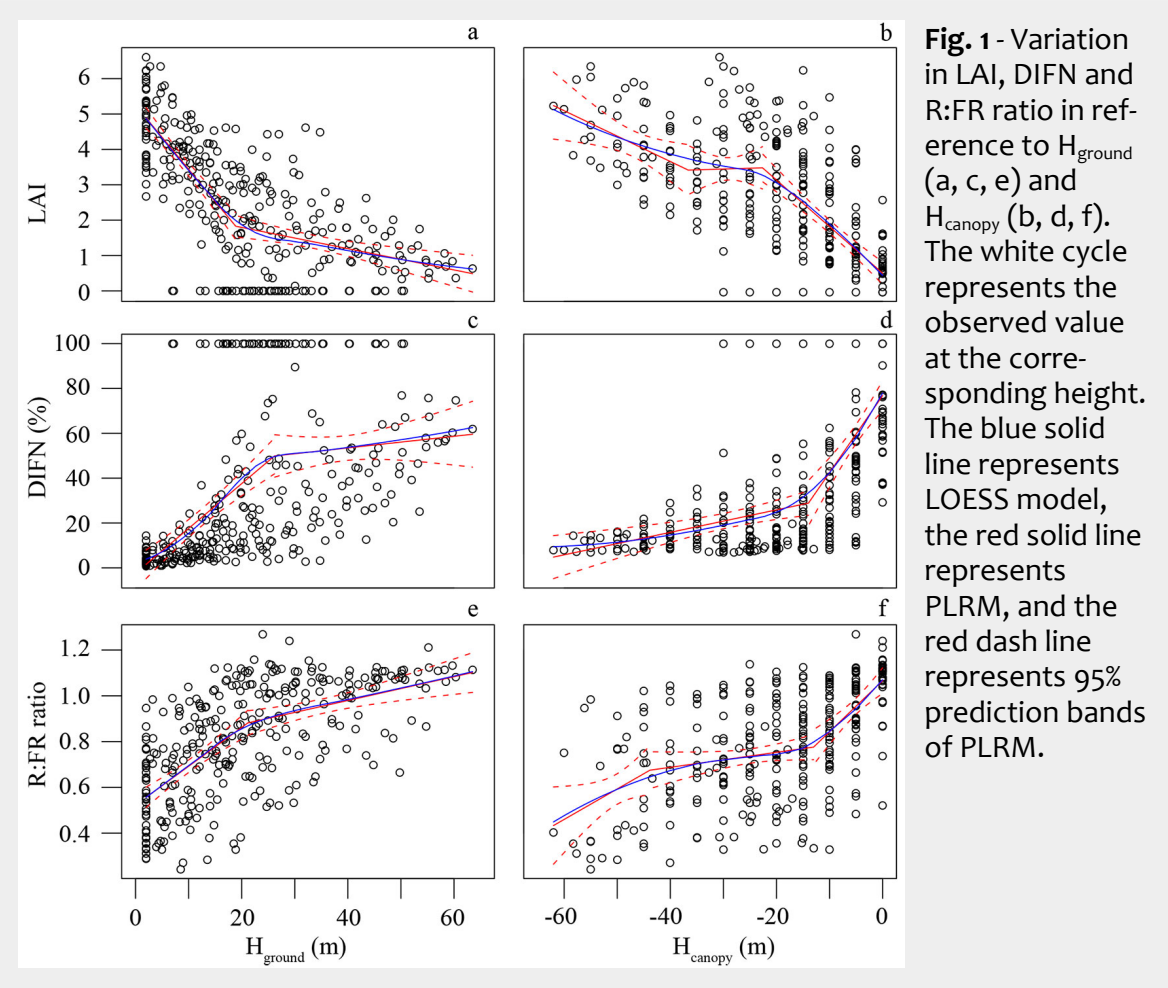


Fig. 2 - Variation in the AMT, ADRT, and

MART with reference to $\mathrm{H}_{\text {ground }}$

(a, c, e ) and

$\mathrm{H}_{\text {canopy }}(\mathrm{b}, \mathrm{d}, \mathrm{f}$ ).

The white cycle

represents the

observed value

at the corre-

sponding height.

The solid blue

line represents

LOESS model,

the red solid line represents

PLRM, and the red dash line

represents $95 \%$

prediction bands of PLRM.
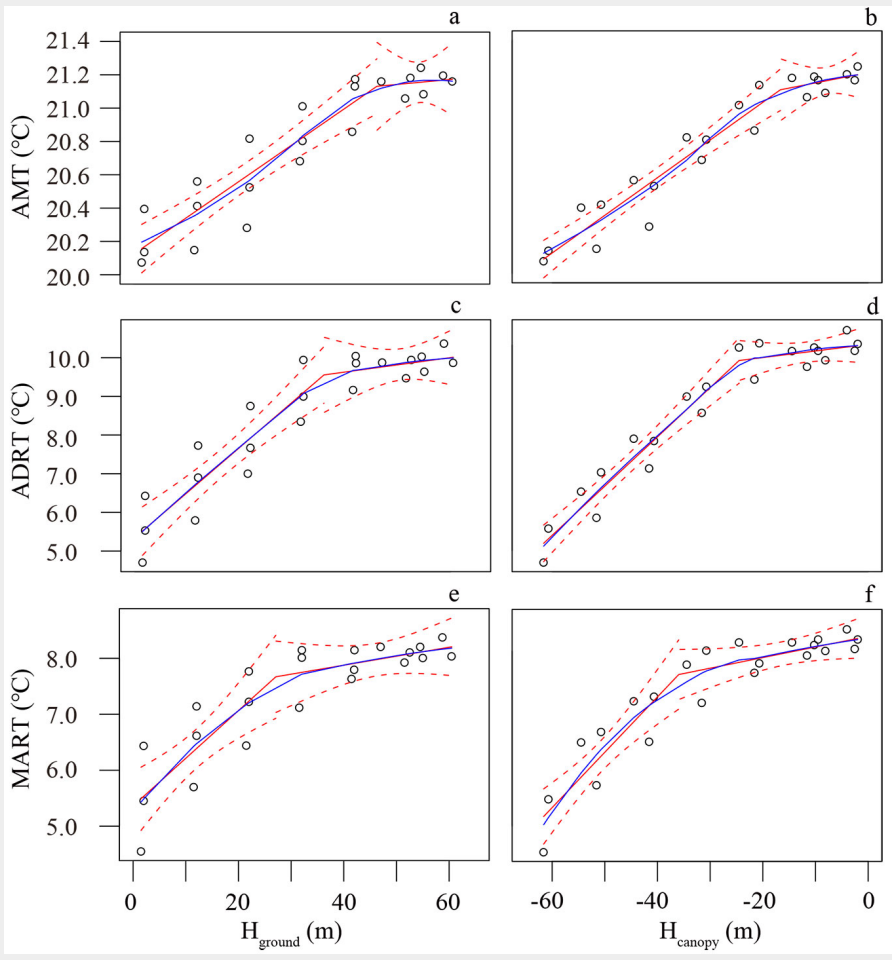

changed with increasing height appeared at $35.9 \pm 5.9 \mathrm{~m}$ high (Fig. $2 \mathrm{c}$ ) or $-24.5 \pm 3.4$ $\mathrm{m}$ under the canopy surface (Fig. $2 \mathrm{~d}$ ). The PLRM regression based on $\mathrm{H}_{\text {canopy }}\left(\mathrm{r}^{2}=\right.$ $0.9490)$ had a better model fit than the model based on $\mathrm{H}_{\text {ground }}\left(r^{2}=0.8738\right)$ for the ADRT.

Regardless of whether the ground or canopy was used for reference, the MART showed a positive relationship with height (Fig. 2e, Fig. 2f), and PLRM suggested a breakpoint at $27.1 \pm 6.7 \mathrm{~m}$ high or $-36.0 \pm$ $4.5 \mathrm{~m}$ under the canopy surface. MART dis-

played a better model fit $\left(r^{2}=0.8788\right)$ when the canopy-referenced method was used compared to the ground-referenced method $\left(r^{2}=0.7707\right)$

Vertical variation in relative humidity

The AMRH in the forest exhibited a negative relationship with height (Fig. 3a, Fig. $3 \mathrm{~b}$ ), and the $r^{2}$ of the PLRM of AMRH vs. canopy-referenced height (0.9227) was higher than that of the model of AMRH vs. ground-referenced height (0.8712). The breakpoint was $-40.7 \pm 5.9 \mathrm{~m}$ under the

Fig. 3 - Variation in the AMRH, ADRRH and MARRH with reference to $\mathrm{H}_{\text {ground }}$ $(\mathrm{a}, \mathrm{c}, \mathrm{e})$ and $H_{\text {canopy }}(b, d, f)$. The white cycle represents the observed value at the corresponding height.

The solid blue line represents

LOESS model, the red solid line represents

PLRM, and the

red dash line

represents $95 \%$ prediction bands of PLRM.
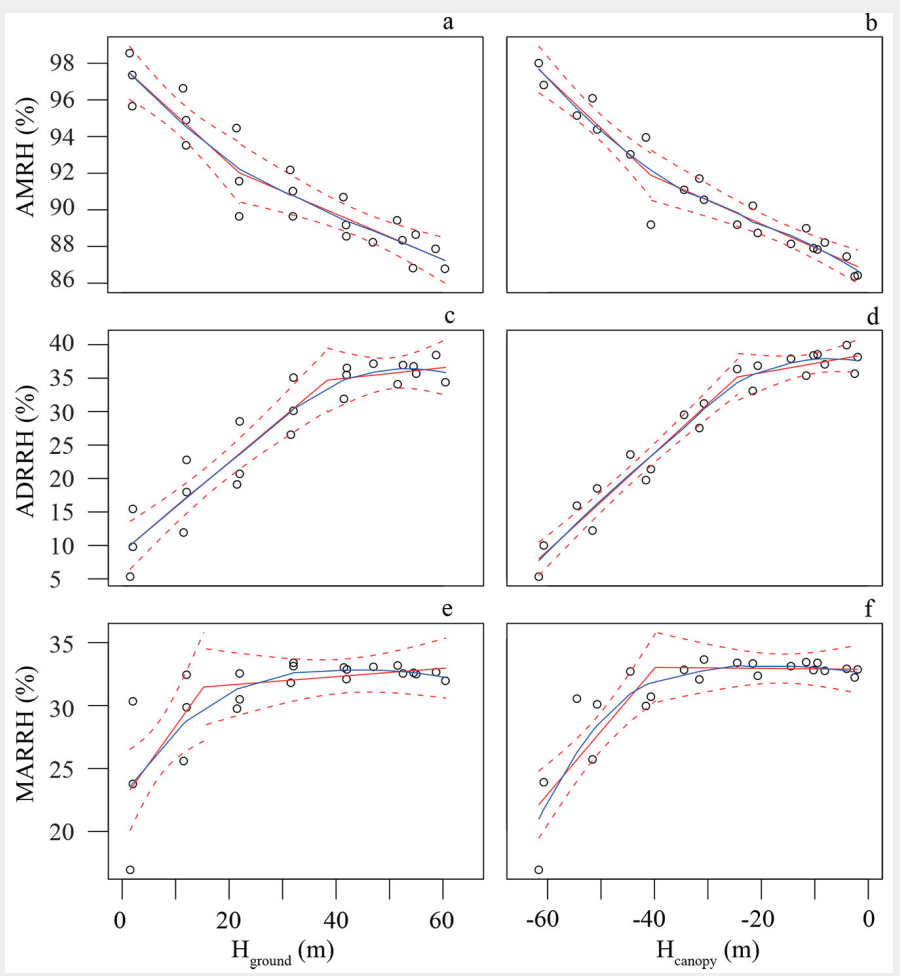

canopy surface $(22.0 \pm 7.8 \mathrm{~m}$ high from the forest floor).

The ADRRH exhibited a positive relationship with the ground-referenced profile from forest floor to $38.4 \pm 5.4 \mathrm{~m}$ (Fig. 3C), and when the canopy was referenced, the breakpoint was at $-24.5 \pm 3.5 \mathrm{~m}$ (Fig. 3d), beyond which the ADRRH became relatively stable with change in height. Canopyreferenced PLRM still showed better fit $\left(r^{2}\right.$ $=0.9563$ ) than did the ground-referenced method $\left(r^{2}=0.8846\right)$.

The MARRH was low near the ground and increased rapidly as the height increased until $15.2 \pm 3.5 \mathrm{~m}$ high (Fig. 3e) or $-40.0 \pm 3.7$ $\mathrm{m}$ (Fig. 3f) under the canopy surface. The PLRM of the MARRH showed better fit with $\mathrm{H}_{\text {canopy }}\left(r^{2}=0.7373\right)$ than with $\mathrm{H}_{\text {ground }}\left(r^{2}\right.$ $=0.5732$ ).

\section{Seasonal variations in air temperature}

The highest MMT in the forest occurred in June at all height levels. The highest value in the profile $\left(24.7^{\circ} \mathrm{C}\right)$ was recorded at $\mathrm{H}_{\text {ground }}=52.5 \mathrm{~m}$ or $\mathrm{H}_{\text {canopy }}=-10 \mathrm{~m}$; the lowest value in the profile $\left(23.6{ }^{\circ} \mathrm{C}\right)$ was recorded at $H_{\text {ground }}=1.5 \mathrm{~m}$ or $\mathrm{H}_{\text {canopy }}=-61.6 \mathrm{~m}$ (Fig. 4a, Fig. 4C). In December, the MMT at each height was the lowest. In the vertical profile, the highest value in December (16.1 ${ }^{\circ} \mathrm{C}$ ) was recorded at $\mathrm{H}_{\text {ground }}=54.5 \mathrm{~m}$ or $\mathrm{H}_{\text {canopy }}=-2 \mathrm{~m}$, and the lowest value $\left(14.9^{\circ} \mathrm{C}\right)$ was recorded at $\mathrm{H}_{\text {ground }}=1.5 \mathrm{~m}$ or $\mathrm{H}_{\text {canopy }}=$ $-61.6 \mathrm{~m}$ (Fig. 4a, Fig. 4c). The temperature difference between the top and bottom of the canopy was the smallest in July, at 0.8 ${ }^{\circ} \mathrm{C}$, and the difference was the largest in March, at $1.9^{\circ} \mathrm{C}$.

The highest MDRT was observed in March. For the vertical profile, the MDRT near the canopy was higher than that in the understory (Fig. 4b, Fig. 4d). The highest MDRT in March was $14.6{ }^{\circ} \mathrm{C}$ and was recorded at $\mathrm{H}_{\text {ground }}=58.7 \mathrm{~m}$ or $\mathrm{H}_{\text {canopy }}=-4 \mathrm{~m}$, and the lowest MDRT in March was $7.0^{\circ} \mathrm{C}$ and was recorded at $\mathrm{H}_{\text {ground }}=1.5 \mathrm{~m}$ or $\mathrm{H}_{\text {canopy }}$ $=-61.6 \mathrm{~m}$.

The lowest MDRT occurred in July. For the vertical profile, the highest MDRT in July was $6.8^{\circ} \mathrm{C}$ and was recorded at $\mathrm{H}_{\text {ground }}$ $=42 \mathrm{~m}$ or $\mathrm{H}_{\text {canopy }}=-20.7 \mathrm{~m}$, and the lowest MDRT in July was $3.1^{\circ} \mathrm{C}$ and was recorded at $H_{\text {ground }}=1.5 \mathrm{~m}$ or $\mathrm{H}_{\text {canopy }}=-61.6 \mathrm{~m}$ (Fig. 4b, Fig. 4d).

The lowest difference in the MDRT in the vertical profiles was in July, at $3.6{ }^{\circ} \mathrm{C}$; and the largest difference was in March, at 7.6 ${ }^{\circ} \mathrm{C}$.

Seasonal variations in relative humidity

The MMRH peaked in August. The maximum was $100 \%$ and was recorded at $\mathrm{H}_{\text {ground }}$ $=1.5 \mathrm{~m}$ or $\mathrm{H}_{\text {canopy }}=-61.6 \mathrm{~m}$, and the minimum was $92 \%$ and was recorded at $\mathrm{H}_{\text {ground }}=$ $54.5 \mathrm{~m}$ or $\mathrm{H}_{\text {canopy }}=-2 \mathrm{~m}$ (Fig. 5a, Fig. $5 \mathrm{C}$ ). The maximum vertical difference in the MMRH was $9 \%$ in August, which also represented the least difference for the entire year.

MMRH was the lowest in March. The maximum was $96 \%$ at $H_{\text {ground }}=1.5 \mathrm{~m}$ or $\mathrm{H}_{\text {canopy }}=-61.6 \mathrm{~m}$, and the minimum was $78 \%$ 
Fig. 4 - The seasonal variation in the MMT and MDRT for different $\mathrm{H}_{\text {ground }}(\mathrm{a}, \mathrm{b})$ and $\mathrm{H}_{\text {canopy }}(\mathrm{c}, \mathrm{d})$ profiles. Light and dark colors represent low temperature and high temperature respectively.
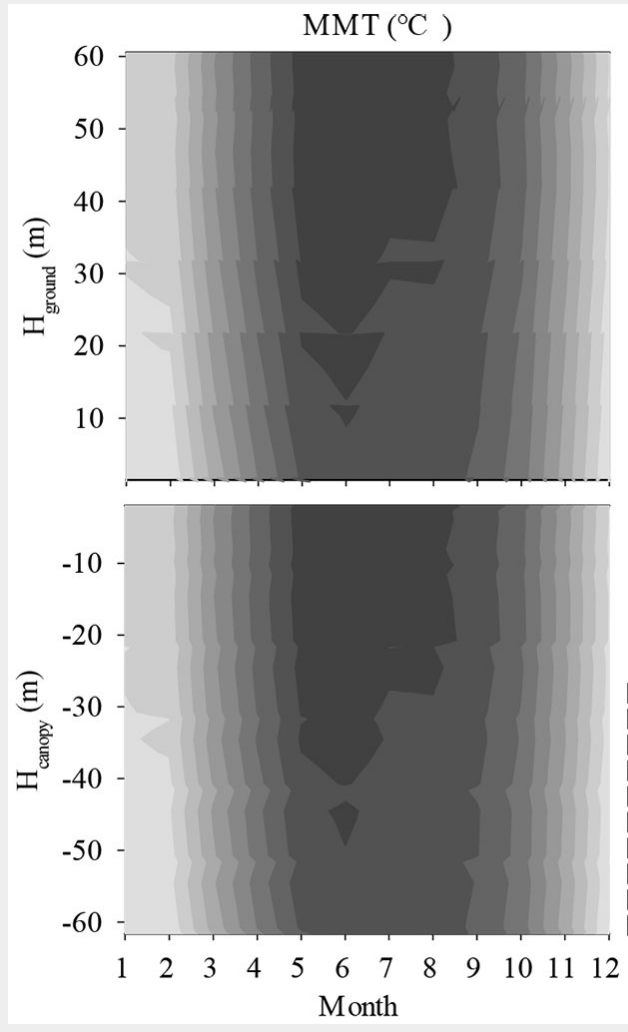

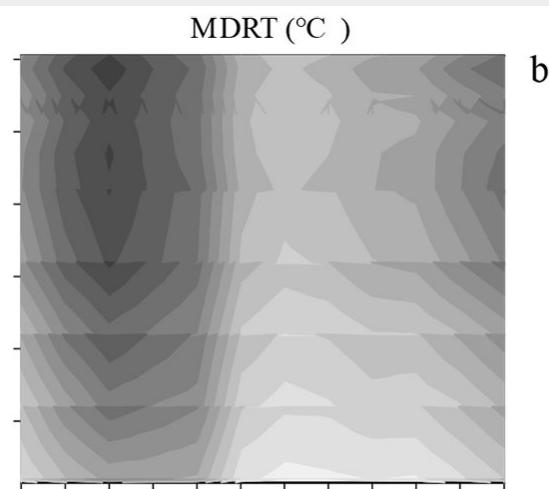

$\mathrm{b}$

C

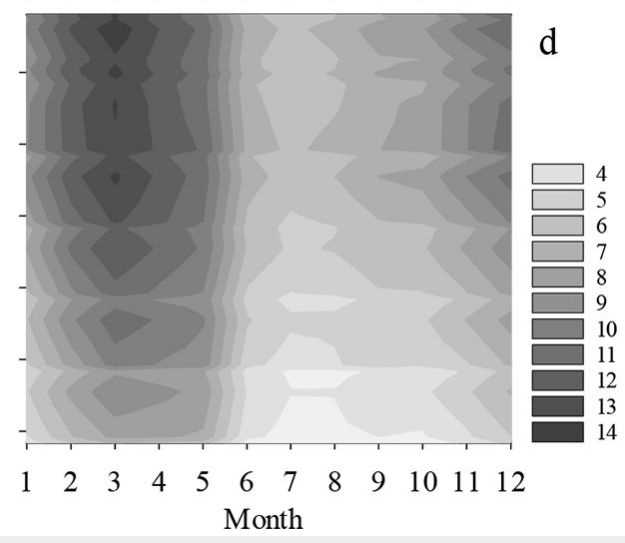

at $\mathrm{H}_{\text {ground }}=60.5 \mathrm{~m}$ or $\mathrm{H}_{\text {canopy }}=-2.6 \mathrm{~m}$ (Fig. 5a, recorded at $\mathrm{H}_{\text {ground }}=1.5 \mathrm{~m}$ or $\mathrm{H}_{\text {canopy }}=-61.6$ Fig. 5c). In March, the MMRH difference $\mathrm{m}$. between the top of the canopy and the MDRRH was the lowest in August (Fig. 5b ground was $17 \%$, the highest value among and $\mathrm{d}$ ). The maximum value in August was all the twelve months throughout the year. The MDRRH peaked in March (Fig. 5b, Fig. $5 d$ ). The maximum was $56 \%$ and was recorded at $\mathrm{H}_{\text {ground }}=58.7 \mathrm{~m}$ or $\mathrm{H}_{\text {canopy }}=-4 \mathrm{~m}$; $\mathrm{m}$ and the minimum was $13 \%$ and was

\section{Discussion}

Vertical profile of light environment within the forest

Variations in the LAI are a consequence of canopy structural attributes (Parker 2020). In this study, the LAI and light environment variables (i.e., DIFN and R:FR ratio) seemed to exhibit steeper variances in the upper
Fig. 5 - The seasonal variation in the MMRH and MDRRH for different $\mathrm{H}_{\text {ground }}$

( $\mathrm{a}, \mathrm{b})$ and $\mathrm{H}_{\text {canopy }}$ values (c, d). Light and dark colors represent low temperature and high temperature, respectively.

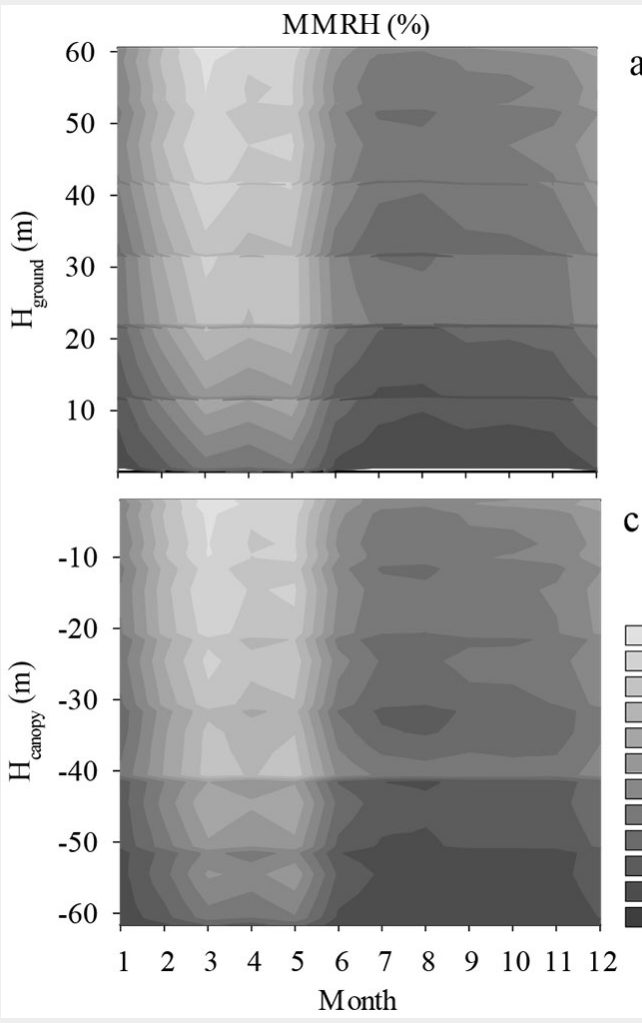

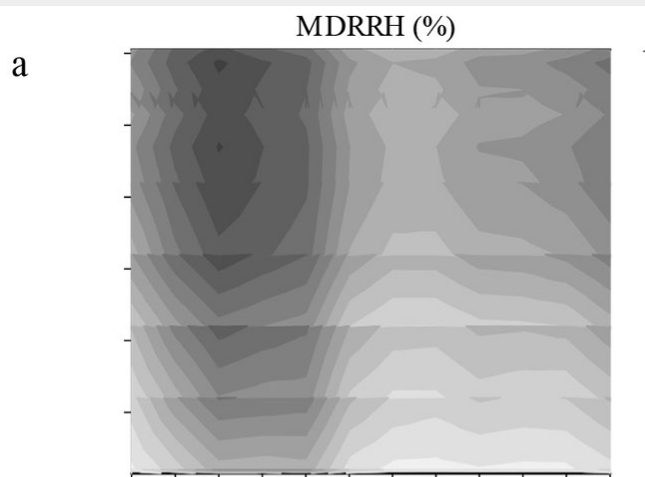
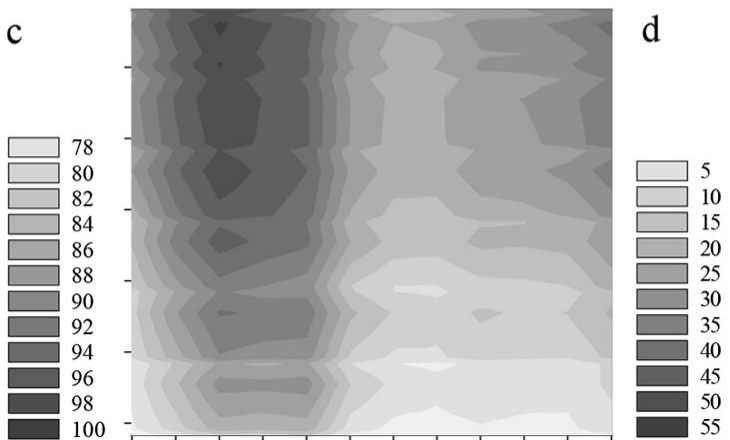

$\begin{array}{llllllllllll}1 & 2 & 3 & 4 & 5 & 6 & 7 & 8 & 9 & 10 & 11 & 12\end{array}$

Month 
canopy with the canopy-referenced ap proach, whereas the ground-referenced method suggested that the variances varied considerably in the lower canopy compared to the upper canopy. Although a similar rapid change based on the ground-referenced method has also been reported for the PPFD (Parker et al. 2019), the ground- and canopy-referenced ap proaches demonstrated a DIFN profile that basically followed Beer's law (Baldocchi \& Collineau 1994, Yirdaw \& Luukkanen 2004) and displayed an exponential relationship with height (Fig. S2 in Supplementary material), and the ground-referenced approach was not consistent with the fact that foliage exhibits significant clumping in the canopy (Landsberg \& Sands 2011). The difference between the ground-referenced and canopy-referenced methods is probably because the former mixed the effect of crown foliage clumping and canopy height heterogeneity together, and a high rugosity is a common feature of old-growth forests (Parker et al. 2019). The canopy-referenced approaches were more consistent with the attenuation of radiation from the top down in forests and more concerned with foliage clumping of tree crowns without the disturbance of height heterogeneity. Thus, these approaches can better quantify the vertical stratification of microclimates.

The LAl $(4.81 \pm 0.97)$ at $1.5-2 \mathrm{~m}$ above the ground in this study was similar to LAI values from previous studies in seasonal rainforests in Xishuangbanna (4.26-6.33 - Dou et al. 2006) and close to the values in two tropical rainforests in Brazil (5.07 \pm 1.5 and 5.05 - Malhado et al. 2009, Parker et al. 2019). However, our results show that the LAl decreased rapidly from the canopy surface to $-22.6 \pm 2.7 \mathrm{~m}$ depth. These findings are different from the vertical distribution of the LAI in the Barro Colorado Island tropical rainforests, where the LAI at $5 \mathrm{~m}$ below the canopy surface contributes approximately $50 \%$ to the understory cumulative LAl (Wirth et al. 2001). That is, deeper depth beneath the canopy is needed to achieve a relatively stable $L A I$ in the forests of our study, as a consequence of differences in statures of canopy tree species. The adult tree of $P$. chinensis was approximately $60 \mathrm{~m}$ tall, its crown occupied $28.04 \%$ (approximately 15-20 m) of the entire adult tree height (Fig. S3 in Supplementary material), and the emergent layer (mainly P. chinensis) was $20 \mathrm{~m}$ higher than the main canopy layer in the local rainforest (Cao \& Zhang 1997, Cao et al. 2008); thus, the tree structure affected the vertical variation in the LAI and light environment within the forest.

The canopy-referenced PLRM in this study suggests that the LAI and the R:FR ratio have secondary breakpoints at $-36.3 \pm$ $6.6 \mathrm{~m}$ and $-43.3 \pm 6.8 \mathrm{~m}$, which is hardly detectable by the ground-referenced model but more consistent with the multilayer structure of local forest. The tropical sea- sonal rainforest in Xishuangbanna contains 3-4 tree layers: the emergent layer (tallest trees up to $60 \mathrm{~m}$ ), main canopy layer (up to $30 \mathrm{~m}$ ) and understory layer (5-18 m, sometimes can be further divided into upper and lower sublayers - Zhu et al. 2006). The coverage of the understory layer is approximately 40\% (Zhu et al. 2006), and the clutter of understory tree species and treelets would further increase the LAI in this layer. The R:FR ratio also showed a similar breakpoint with canopy-referenced height, which probably because high LAI indicates a greater number of leaves and thus higher absorption of red light (Lee 1989, Pons 1992).

The DIFN at $1.5-2 \mathrm{~m}$ above ground in this forest was $4.18 \pm 3.33 \%$, which was close to that of the light environment at $1 \mathrm{~m}$ above the forest floor $(5.7 \%)$ in a primary moist tropical forest in Brazil (Parker et al. 2019) and was within the normal range of $2-7 \%$ on the ground in forests (Baldocchi \& Collineau 1994). Considering the mechanical layout, method in this study did not deliberately avoid canopy gaps, the mean ground DIFN in this study might already indicate the light heterogeneity of the local forest surface in its natural state, including canopy gaps.

The DIFN in this study could not reach saturation on canopy surface (76.95 \pm $24.19 \%$ ), mainly because the canopy in the tropical rainforest was uneven. Even on the top surface of a tree crown, shadow projection from both surrounding emergent trees and topography should be considered in light transmission around the canopy.

In this study, the R:FR ratio at $1.5-2 \mathrm{~m}$ above the ground was $0.55 \pm 0.18$, which was close to the mean value in a wet tropical forest in Costa Rica (0.51 - Capers \& Chazdon 2004) but higher than the normal understory level (0.23) reported earlier (Daws et al. 2002). This difference may be due to the small gaps included in this study plot, and environmental factors, including the degree of canopy closure, the canopy structure, and the presence of clouds, could also affect the R:FR ratio (Endler 1993). In the understory, the relationship between the R:FR ratio and the diffuse transmittance is logarithmic (Muraoka et al. 2001, Capers \& Chazdon 2004), and LAI calculations also depend on the logarithmic transformation of the DIFN (Welles \& Cohen 1996); as result, the R:FR ratio showed a sharp change from the top surface to a depth of $-13.0 \pm 2.5 \mathrm{~m}$ into the canopy, which was linearly correlated with the variation in the logarithmic DIFN ( $F=$ $364.7, r^{2}=0.5422, P<0.001-$ Fig. S4a) and LAI $\left(F=341.8, r^{2}=0.5261, P<0.001-\right.$ Fig. $\mathrm{S} 4 \mathrm{~b}$ in Supplementary material).

\section{Vertical profiles of temperature within the forest}

For both the air temperature and the $\mathrm{RH}$, the $r^{2}$ values of the PLRMs were all lower when using $H_{\text {ground }}$ than when using $H_{\text {canopy }}$
(Tab. S2 in Supplementary material). Since the canopy is the first interface layer connecting the forest with the external energy environment, the canopy-referenced approach could better describe the attenuation of solar energy after it enters the canopy.

The AMT varied from $21.2 \pm 0.04$ at the canopy surface to $20.2 \pm 0.2$ on the forest floor, which is consistent with the assumption that forests reduce the understory air temperature in tropical (Ewers \& BanksLeite 2013) and temperate (Didham \& Ewers 2014) areas. Previous local studies have also reported higher temperatures in the canopy than in the understory (Yang et al. 2009), but these studies failed to provide a continuous temperature variation curve in the vertical profile. Previous studies from another local tropical rainforest have reported that the air temperature increased as the height in the understory increased, and the diurnal range of the air temperature at the canopy layer exceeded that in the understory (Liu et al. 2001, Zhang et al. 2004). These results indicated that the upper canopy is an "edge" where heat flow degression occurs vertically from the atmosphere above the canopy to the understory (Malcolm 1998). The AMT and ADRT showed similar breakpoints $(-16.7 \pm 6.5 \mathrm{~m}$ and $-24.5 \pm 3.4 \mathrm{~m})$ with LAl in the upper canopy $(-22.6 \pm 2.7 \mathrm{~m})$, and the LAl is the major factor limiting the transmission of heat flow in forests (Malcolm 1998, Didham \& Ewers 2014). Although $41.74 \%$ of the LAl was concentrated from o $\mathrm{m}$ to $15 \mathrm{~m}$ below the top of the canopy, the emergent crown of $P$. chinensis was exposed to full sunlight above the main canopy layer, and the diurnal and annual variations in illumination from all directions ensured that the differences in the air temperature (and $\mathrm{RH}$ ) were not affected by overhead shading. The turbulence is another reason to keep difference in temperature (and humidity) stable, which could mix warm air in upper canopy, and lead a completely decoupled course of temperature and humidity in the understory (Kira \& Yoda 1989, Ribeiro et al. 1996, Motzer 2005).

\section{Vertical profiles of humidity within the forest}

Forest canopies have a strong moderating effect on irradiance and wind speed below and within the canopy, and the air temperature moderately decreases within vegetation. These microclimatic trends enhance the RH in the understory (Fanourakis et al. 2020). The AMRH was $10 \%$ higher $1.5-2$ $\mathrm{m}$ above the ground $(97 \pm 1 \%)$ than in the upper canopy $(87 \pm 1 \%)$ in this study, close to previously reported values for AMRH of $82-85 \%$ in the rainforest canopy and $80-92 \%$ in the understory (Gallery 2014).

The diurnal and annual ranges in $\mathrm{RH}$ in the vertical profile are important for the settlement of some specific species, such as epiphytes (Shen et al. 2018) and amphibians (Brooks \& Kyker-Snowman 2008). This 
is particularly true for the forest in our study, because this region is predominated by a typical tropical monsoon climate with a distinct dry season from November to April yearly (Cao et al. 2006). Although the ADRRH in the upper canopy (higher than $-24.5 \pm 3.5 \mathrm{~m}$ ) exceeded $30 \%$, and similar diurnal $\mathrm{RH}$ differences have been reported in Amazonian rainforests ( $\mathrm{RH}$ varies from $70 \%$ to $100 \%$ - Mendes \& Marenco 2017) and in French Guiana (RH varies from 81 to $93 \%$ Gehrig-Downie et al. 2011), the ADRRH decreased to $10 \pm 5 \%$ at $1.5-2 \mathrm{~m}$ above ground. A similar vertical gradient in the diurnal range of the $\mathrm{RH}$ in the dry season has been reported in another local tropical seasonal rainforest (Liu et al. 2001).

The PLRM estimated the segment of the ADRRH to be at $-24.5 \pm 3.5 \mathrm{~m}$ in $\mathrm{H}_{\text {canopy }}$, which was consistent with the crown structure of $P$. chinensis in the emergent layer (Fig. S3 in Supplementary material). The breakpoints for AMRH, MARRH and MART $(-40.7 \pm 5.9 \mathrm{~m},-39.8 \pm 3.7 \mathrm{~m}$ and $-36.0 \pm 4.5$ $m$, respectively) were similar to the breakpoint for LAl in the understory $(-36.6 \pm 6$ $\mathrm{m})$, which may have resulted from high plant density in the understory layer limiting air circulation around plants (Poorter et al. 2012), and a valley across the crane plot could compensate for the lack of precipitation in the dry season.

The mean value of the MMRH in the profile was the highest in August and the lowest in March; these extreme values occurred approximately one month later than the annual extreme values of the local precipitation (local precipitation is the highest in July and the lowest in February - Deng \& Tang 2010). Although the correlation between the mean value of the MMRH in the profile and the precipitation in the same month was not high $(P C C=0.376, P>0.05$ - Tab. S4 in Supplementary material), the mean value of the MMRH in the profile was closely correlated with the precipitation of the previous month $(\mathrm{PCC}=0.651, P<0.05)$, which may be due to the lag effect of local forests on hydrological processes. The soil in local tropical forests has a good water conservation capacity, which significantly increases and delays the base flow (Gao et al. 2009), and this hysteresis effect in local hydrologic process is also embodied in the soil water content and $\mathrm{RH}$ in the understory.

\section{Conclusions}

When the canopy was used as the reference, the $r^{2}$ values for all microclimatic factors exceeded those for the ground-referenced model, which indicates that the canopy-referenced approach can better describe the microclimatic variation in the vertical profile within the forest, especially when the canopy structure is heterogeneous and the vertical variation in micrometeorological aspects is nonlinear. The canopy-referenced approach avoided interference from canopy height heterogeneity and was more consistent with the LAI and the foliage distribution in the canopy. This approach therefore exhibited a better fit when used to model the light attenuation process in the vertical profile of the forest.

At least two breakpoints were observed in vertical microclimate profiles of local forests, at approximately $-20 \mathrm{~m}$ (for AMT, ADRT and ADRRH) and $-40 \mathrm{~m}$ (for AMRH, MARRH and MART) under the canopy, which corresponded to the transition points for LAl in the vertical profile. At the first breakpoint (approximately $-20 \mathrm{~m}$ ), crown structure of canopy species led to a sharp change in light environment variables such as the DIFN and the R:FR ratio, and microclimatic factors such as the annual mean temperature and the diurnal ranges in temperature and $\mathrm{RH}$; however, turbulence kept the annual ranges in temperature and $\mathrm{RH}$ high but stable in the emergent layer. At the second breakpoint (approximately $-40 \mathrm{~m}$ ), the high plant density in the understory layer further increased LAI, limited air circulation around plants, and maintained a low but stable environment in terms of the annual mean $\mathrm{RH}$ and the annual ranges in temperature and $\mathrm{RH}$. These discontinuous variations in microclimatic factors can be better observed with the canopy-referenced approach. Canopy-referenced microclimatic profiles may improve our understanding of vertical variation in species composition and biodiversity in tropical forests with high canopies.

\section{List of abbreviations}

The following abbreviations have been used throughout the paper:

- LAI: leaf area index

- DIFN: diffuse non-interceptance

- MTA: mean tilt angle of leaves

- R:FR: red to far-red light ratio

- PPFD: photosynthetic photon flux density

- AMT: annual mean temperature

- MMT: monthly mean temperature

- MDRT: monthly mean diurnal range of temperature

- ADRT: annual mean diurnal range of temperature

- ART: annual range of temperature

- MART: mean annual range of temperature

- $\mathrm{RH}$ : relative humidity

- AMRH: annual mean relative humidity

- MMRH: monthly mean relative humidity

- MDRRH: monthly mean diurnal range of relative humidity

- ADRRH: annual mean diurnal range of relative humidity

- ARRH: annual range of relative humidity

- MARRH: mean annual range of relative humidity

\section{Acknowledgements}

$M C, X D$, and YD conceived of the ideas and designed the experiment; YD wrote the first draft of the manuscript; JD, WZ, and SY collected and analyzed the data; ZT and QS contributed considerably to the revisions of the manuscript. We thank Dr. Jin Wu for his valuable suggestions on our manuscript and Mr. Hanxiang Yan, Mr. Mingzhong Liu and Mr. PinPing Zeng for their assistance with the field work. We thank the National Forest Ecosystem Research Station at Xishuangbanna, Xishuangbanna Tropical Botanical Garden, Chinese Academy of Sciences, for assistance in routine maintenance and technical support in the crane plot. We also thank the Management Bureau of Xishuangbanna National Nature Reserve for permission to conduct field work in the nature reserve. This work was supported by $\mathrm{Na}$ tional Science Foundation of China (grant no. 32061123003 and no. 41771099) and the Chinese Academy of Sciences 135 Program (grant no. 2017XTBG-T01) and the Field Station Foundation of the Chinese Academy of Sciences.

\section{References}

Baldocchi D, Collineau S (1994). The physical nature of solar radiation in heterogeneous canopies: spatial and temporal attributes. In: “Exploitation of Environmental Heterogeneity by Plants: Ecophysiological Processes Above- and Belowground" (Caldwell MM, Pearcy RW eds). Academic Press, San Diego, CA, USA, pp. 21-71. [online] URL: http://books.google.com/books? id=59Tp1ulggfoC

Bazzaz FA, Wayne PM (1994). Coping with environmental heterogeneity: the physiological ecology of tree seedling regeneration across the gap-understory continuum. In: “Exploitation of Environmental Heterogeneity by Plants: Ecophysiological Process Above and Below Ground" (Caldwell MM, Pearcy RW eds). Academic Press, San Diego, CA, USA, pp. 349-390.

Brooks RT, Kyker-Snowman TD (2008). Forest floor temperature and relative humidity following timber harvesting in southern New England, USA. Forest Ecology and Management 254: 65-73. - doi: 10.1016/j.foreco.2007.07.028 Cao M, Zhang JH (1997). Tree species diversity of tropical forest vegetation in Xishuangbanna, SW China. Biodiversity and Conservation 6: 995-1006. - doi: 10.1023/A:1018367630923

Cao M, Zou XM, Warren M, Zhu H (2006). Tropical forests of Xishuangbanna, China. Biotropica 38: 306-309. - doi: 10.1111/j.1744-7429.2006.0014 $6 . x$

Cao M, Zhu H, Wang H, Lan GY, Hu YH, Zhou SS, Deng XB, Cui JY (2008). Xishuangbanna tropical seasonal rainforest dynamics plot: tree distribution maps, diameter tables and species documentation. Yunnan Science and Technology Press, Kunming, China, pp. 1-13.

Capers RS, Chazdon RL (2004). Rapid assessment of understory light availability in a wet tropical forest. Agricultural and Forest Meteorology 123: 177-185. - doi: 10.1016/j.agrformet.20 03.12.009

Daws MI, Burslem DFRP, Crabtree LM, Kirkman $P$, Mullins CE, Dalling JW (2002). Differences in seed germination responses may promote coexistence of four sympatric piper species. Functional Ecology 16: 258-267. - doi: 10.1046/j.13652435.2002.00615.x

Deng X, Tang J (2010). Observation of China's ecosystem positioning and research datasetforest ecosystem volume - Xishuangbanna Sta- 
tion, Yunnan. China Agriculture Press, Beijing, pp. 1-7.

Deng $Y$, Deng $X$, Dong J, Zhang W, Hu T, Naka mura A, Song X, Fu P, Cao M (2020). Detecting growth phase shifts based on leaf trait variation of a canopy dipterocarp tree species (Parashorea chinensis). Forests 11 (11): 1145. - doi: 10.3390/f11111145

Didham RK, Ewers RM (2014). Edge effects disrupt vertical stratification of microclimate in a temperate forest canopy. Pacific Science 68: 493-508. - doi: 10.2984/68.4.4

Dou J, Zhang Y, Zhao S, Song Q (2006). Characteristics of radiation at different heights within the canopy of a tropical seasonal rain forest in Xishuangbanna, Southwest China. Journal of Beijing Forestry University 28: 15-21.

Endler JA (1993). The color of light in forests and its implications. Ecological Monographs 63: 127. - doi: $10.2307 / 2937121$

Engelbrecht BMJ, Herz HM (2001). Evaluation of different methods to estimate understorey light conditions in tropical forests. Journal of Tropical Ecology 17: 207-224. - doi: 10.1017/So26 6467401001146

Ewers RM, Banks-Leite C (2013). Fragmentation impairs the microclimate buffering effect of tropical forests. PLoS One 8 (3): e58093. - doi: 10.1371/journal.pone.0058093

Fanourakis D, Aliniaeifard S, Sellin A, Giday $H$, Körner O, Rezaei Nejad A, Delis C, Bouranis D, Koubouris G, Kambourakis E, Nikoloudakis N, Tsaniklidis G (2020). Stomatal behavior following mid- or long-term exposure to high relative air humidity: a review. Plant Physiology and Biochemistry 153: 92-105. - doi: 10.1016/j.plaphy. 2020.05.024

Gallery RE (2014). Ecology of tropical rain forests. In: "Ecology and the Environment" (Monson RK ed). Springer, New York, NY, pp. 247-272.

Gao F, Zhang Y, Liu W, Tang J, Deng X (2009). Characteristics of base flow in tropical seasonal rainforest catchments in Xishuangbanna of Yunnan Provice, Southwest China. Chinese Journal of Applied Ecology 28: 1949-1955.

Gehrig-Downie C, Obregón A, Bendix J, Gradstein SR (2011). Epiphyte biomass and canopy microclimate in the tropical lowland cloud forest of French Guiana. Biotropica 43: 591-596. doi: 10.1111/j.1744-7429.2010.00745.x

Kenzo $T$, Inoue $Y$, Yoshimura $M$, Yamashita $M$, Tanaka-Oda A, Ichie T (2015). Height-related changes in leaf photosynthetic traits in diverse Bornean tropical rain forest trees. Oecologia 177: 191-202. - doi: 10.1007/s00442-014-3126-0

Kira T, Yoda K (1989). Vertical stratification in microclimate. In: "Tropical Rainforest Ecosystems - Biogeographical and Ecological studies” (Werger $M$ ed). Elsevier, Amsterdam, Netherlands, pp. 55-71. - doi: 10.1016/B978-0-444-42755-7.500 09-2

Landsberg J, Sands P (2011). Physiological ecology of forest production. Academic Press, Oxford, UK, pp. 14-47.

Lee DW (1989). Canopy dynamics and light climates in a tropical moist deciduous forest in India. Journal of Tropical Ecology 5: 65-79. - doi: $10.1017 /$ So266467400003229

LI-COR (2021). LAl-2200C plant canopy analyzer instruction manual v984-14112. [online] URL: http://www.licor.com/documents/fqin5mlu8c1a 7zir5qel

Liu W, Zhang K, Wang C, Li H, Duan W (2001). The microclimate of dew and fog formation on canopy layer in the dry season in Xishuangbanna tropical rain forest. Acta Ecologica Sinica 21: 496-491. [online] URL: http://europepm c.org/article/cba/347449

Malcolm JR (1998). A model of conductive heat flow in forest edges and fragmented landscapes. Climatic Change 39: 487-502. - doi: 10.1023/A:1005376603186

Malhado AC, Costa MH, De Lima FZ, Portilho KC, Figueiredo DN (2009). Seasonal leaf dynamics in an Amazonian tropical forest. Forest Ecology and Management 258: 1161-1165. - doi: 10.1016/j. foreco.2009.06.002

Mendes KR, Marenco RA (2017). Stomatal opening in response to the simultaneous increase in vapor pressure deficit and temperature over a 24-h period under constant light in a tropical rainforest of the central Amazon. Theoretical and Experimental Plant Physiology 29: 187-194. doi: 10.1007/s40626-017-0094-x

Motzer T (2005). Micrometeorological aspects of a tropical mountain forest. Agricultural and Forest Meteorology 135: 230-240. - doi: 10.1016/j.agrformet.2005.11.019

Muggeo V (2021). Segmented: regression models with break-points / Change-points estimation. $\mathrm{R}$ fondation for statistical compution. $\mathrm{R}$ package version 1:3-4. [online] URL: http://cran. r-project.org/package=segmented

Muraoka H, Hirota H, Matsumoto J, Nishimura S, Tang Y, Koizumi H, Washitani I (2001). On the convertibility of different microsite light availability indices, relative illuminance and relative photon flux density. Functional Ecology 15: 798803. - doi: 10.1046/j.0269-8463.2001.00581.x Nakamura A, Kitching RL, Cao M, Creedy TJ, Fayle TM, Freiberg $M$, Hewitt CN, Itioka T, Koh LP, Ma K, Malhi Y, Mitchell A, Novotny V, Ozanne CMP, Song L, Wang H, Ashton LA (2017). Forests and their canopies: achievements and horizons in canopy science. Trends in Ecology and Evolution 32: 438-451. - doi: 10.1016/j.tree.2017. 02.020

Parker GG (2020). Tamm review: Leaf Area Index (LAI) is both a determinant and a consequence of important processes in vegetation canopies. Forest Ecology and Management 477 (1): 118496. - doi: 10.1016/j.foreco.2020.118496

Parker GG, Fitzjarrald DR, Sampaio ICG (2019). Consequences of environmental heterogeneity for the photosynthetic light environment of a tropical forest. Agricultural and Forest Meteorology 278 (18): 107661. - doi: 10.1016/j.agrfor met.2019.107661

Poley LG, McDermid GJ (2020). A systematic review of the factors influencing the estimation of vegetation aboveground biomass using unmanned aerial systems. Remote Sensing 12: 1052. - doi: $10.3390 /$ rs 12071052

Pons TL (1992). Seed responses to light. In: "Seeds: The Ecology of Regeneration in Plant Communities" (Fenner $M$ ed). CAB International, Wallingford, UK, pp. 259-284. - doi: 10.1079/9780851994321.0237

Poorter $\mathrm{H}$, Fiorani $F$, Stitt $M$, Schurr $U$, Finck $A$, Gibon Y, Usadel B, Munns R, Atkin OK, Tardieu $F$ (2012). The art of growing plants for experi- mental purposes: a practical guide for the plant biologist. Functional Plant Biology 39: 821-838. doi: $10.1071 / F_{12} 028$

R Core Team (2020). R: a language and environment for statistical computing. R Fondation for Statistical Compution, Vienna, Austria. [online] URL: http://www.r-project.org

Ribeiro A, Victoria LA, Martinelli LA, Moreira MZ, Roberts JM (1996). The isotopic composition of atmospheric water vapour inside a canopy in Amazonian forest: vertical and diurnal variation. In: "Amazonian Deforestation and Climate" (Gash JHC, Nobre CA, Roberts JM, Victoria RL eds). John Wiley and Sons, New York, USA, pp. 163-173.

Scheffers BR, Evans TA, Williams SE, Edwards DP (2014). Microhabitats in the tropics buffer temperature in a globally coherent manner. Biology Letters 10 (12): 20140819. - doi: 10.1098/rsbl.20 14.0819

Shen T, Corlett RT, Song L, Ma WZ, Guo XL, Song Y, Wu Y (2018). Vertical gradient in bryophyte diversity and species composition in tropical and subtropical forests in Yunnan, SW China. Journal of Vegetation Science 29: 1075-1087. doi: 10.1111/jvs.12692

Tomal JH, Ciborowski JJH (2020). Ecological models for estimating breakpoints and prediction intervals. Ecology and Evolution 10: 1350013517. - doi: 10.1002/ece3.6955

Turnbull MH, Yates DJ (1993). Seasonal variation in the red/far-red ratio and photon flux density in an Australian sub-tropical rainforest. Agricultural and Forest Meteorology 64: 111-127. - doi: 10.1016/0168-1923(93)90096-Z

Welles JM, Cohen S (1996). Canopy structure measurement by gap fraction analysis using commercial instrumentation. Journal of Experimental Botany 47: 1335-1342. - doi: 10.1093/jxb/ 47.9.1335

Wirth R, Weber B, Ryel RJ (2001). Spatial and temporal variability of canopy structure in a tropical moist forest. Acta Oecologica 22: 235244. - doi: 10.1016/S1146-609X(01)01123-7

Yang Z, Zhang Y, Yu G, Zhao S, Song Q, Gao J (2009). Characteristics of canopy and air temperature in tropical seasonal rainforests in $\mathrm{Xi}$ shuangbanna. Chinese Journal of Applied Ecology 28: 845-849. [online] URL: http://en.cn ki.com.cn/Article_en/CJFDTotal-STXZ20090501 1.htm

Yirdaw E, Luukkanen O (2004). Photosynthetically active radiation transmittance of forest plantation canopies in the Ethiopian highlands. Forest Ecology and Management 188: 17-24. doi: 10.1016/j.foreco.2003.07.024

Zhang Y, Dou J, Yu G, Zhao S, Song Q, Sun X (2005). Characteristics of solar radiation and its distribution above the canopy of tropical seasonal rainforest in Xishuangbanna, Southwest China. Journal of Beijing Forestry University 27: 17-25. [online] URL: http://j.bjfu.edu.cn/en/art icle/id/9016

Zhang Y, Zhao S, Dou J, Liu Y (2004). Temporal and spatial distribution characteristics of thermal effects in a tropical seasonal rainforest in Xishuangbanna, Southwest of China. Journal of Beijing Forestry University 26: 1-7.

Zhu H, Cao M, Hu HB (2006). Geological history, flora, and vegetation of Xishuangbanna, southern Yunnan, China. Biotropica 38: 310-317. - doi: 
$10.1111 / \mathrm{j} \cdot 1744-7429.2006 .00147 \cdot x$

\section{Supplementary Material}

Tab. S1 - Summary statistics for microclimatic factors in the crane plot.

Tab. S2 - Estimates and 95\% confidence intervals of the thresholds of the PLRM results for microclimatic factors vs. Height.
Tab. S3 - Estimates and 95\% confidence intervals of the slopes of the PLRM results for microclimatic factors vs. Height.

Tab. S4 - Pearson correlation coefficient (PCC) of the MMT, MMRH, and precipitation.

Fig. S1 - Distribution of observation profiles in the orthophoto map and the digital surface model.
Fig. S2 - Variation in natural logarithm transformed DIFN in reference to height. Fig. S3 - The relationship between individual tree height and crown depth of P. Chinensis.

Fig. S4 - Variation in the In (DIFN) (a) and LAI (b) with reference to the R:FR ratio.

Link: Deng_3780@supplo01.pdf 